\title{
Smoking-dependent and haplotype-specific effects of endothelial nitric oxide synthase gene polymorphisms on angiographically assessed coronary artery disease in Caucasian- and African-Brazilians
}

\author{
Domingos L.S. Rios ${ }^{a, b, *}$, Lorenza O. D’Onofrio ${ }^{b, c}$, Joares K. Souza ${ }^{b, c}$, Amália M. Queiroz $^{b}$, \\ Luciana Raduy-Maron $^{\mathrm{b}, \mathrm{c}}$, Naila Silva-Neto ${ }^{\mathrm{b}}$, Heitor G. Carvalho ${ }^{\mathrm{d}}$, \\ Ademar Santos-Filho ${ }^{\mathrm{d}}$, Bernardo Galvão-Castro ${ }^{\mathrm{b}, \mathrm{c}}$

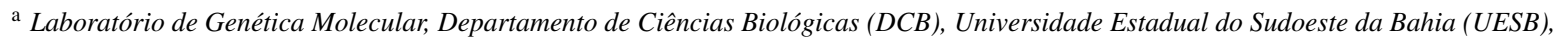 \\ Avenida José Moreira Sobrinho, s/n, Bairro-Jequiezinho, 45.200-000 Jequié, BA, Brazil \\ ${ }^{\mathrm{b}}$ Centro de Pesquisas Gonçalo Moniz. (CPqGM), Fundação Oswaldo Cruz (FIOCRUZ), Salvador, BA, Brazil \\ ${ }^{\mathrm{c}}$ Fundação Bahiana para o Desenvolvimento das Ciências, Salvador, BA, Brazil \\ ${ }^{\mathrm{d}}$ Hospital Santa Izabel, Salvador, BA, Brazil
}

Received 3 February 2006; received in revised form 5 May 2006; accepted 22 May 2006

Available online 13 July 2006

\begin{abstract}
The nitric oxide produced by endothelial nitric oxide synthase (eNOS) plays a pivotal role in protecting the arterial wall from damages and atherosclerosis. The T-786C, the 27-bp repeat in intron 4, and the E298D eNOS gene polymorphisms were studied in 715 Brazilian patients (447 Caucasian- and 268 African-Brazilians) who underwent coronary angiography. The $-786 \mathrm{C}$ frequency was increased in coronary artery disease (CAD) cases with significant lesions ( $\geq 50 \%$ luminal obstruction) when compared with lesion-free controls; this difference was detected in smokers but not in nonsmokers, both in Caucasian- $(p=0.011)$ and African-Brazilians $(p=0.005)$. The interaction between $-786 \mathrm{C}$ carriers and smoking was an independent CAD predictor (OR: 2.9, 95\% CI: 1.4-5.9; $p=0.003$ ) in multiple logistic regression. The 298D mutation frequency was also higher among CAD cases $(p=0.036)$ in African-Brazilian smokers, but this effect was not independent from other variables in the regression model. Though not associated with CAD, the 4-repeat allele combined with different T-786C alleles showed protective and susceptible effects in Caucasian-Brazilian smokers. The $-786 \mathrm{C} / 4$-repeat/298E haplotype frequency was higher $(p=0.020)$, whereas $-786 \mathrm{~T} / 4$-repeat/298E was lower $(p=0.023)$ in these cases. These results showed a smoking-dependent effect of the T-786C eNOS polymorphism on CAD in both Caucasian- and African-Brazilians. Additionally, the haplotype analysis revealed different eNOS haplotypes associated with protection and susceptibility to the disease.
\end{abstract}

(C) 2006 Elsevier Ireland Ltd. All rights reserved.

Keywords: Coronary artery disease; Endothelial nitric oxide synthase; Polymorphisms; African-Brazilians

\section{Introduction}

Coronary artery disease (CAD) is the leading cause of death in the world. The underlying pathogenesis involves several environmental and genetic factors that also interact among themselves causing the development of atheroscle-

\footnotetext{
* Corresponding author. Tel.: +55 733526 8660; fax: +55 7335256683 .

E-mail addresses: drios@uesb.br, domingosrios@hotmail.com (D.L.S. Rios).
}

rotic plaque [1]. Nitric oxide, synthesized by endothelial cells and platelets from L-arginine, has a key role in the endothelial function protecting the arterial wall from developing atherosclerotic lesions. This metabolite acts in lowering the arterial tonus, inhibits platelet aggregation and thrombus formation. It also limits the arterial wall-inflammatory response to risk factor damages by inhibiting the leukocyte adhesion and migration through the endothelium and lowering the lipoprotein particle oxidation [2]. 
The endothelial nitric oxide synthase (eNOS) gene presents some polymorphisms that have been previously associated with angiographically assessed CAD or myocardial infarct (MI) [3-5]. A functional variant in the eNOS promoter (T-786C) is associated with reduction in the promoter efficiency and the level of expressed enzyme leading to increased CAD risk [6-8]. The eNOS gene also presents a variable number of tandem repeats ( $27 \mathrm{bp}$ ) in intron 4 , and the rare 4-repeat allele was associated with CAD [9]. Another common eNOS mutation is located in exon 7 and causes the change of glutamine (E) to aspartic acid (D) in codon 298. The 298D allele has been previously associated with endothelial function [10] and CAD risk in some [11-13] but not all studies [14]. Additionally, few studies have addressed the combined effect of these three eNOS polymorphisms forming haplotypes and their effects on cardiovascular disease, and some of these investigations showed protective and susceptible eNOS haplotype effects $[8,15]$.

As predicted by the multifactorial nature of CAD, some candidate gene effects on disease phenotypes seem to be triggered by environmental factors $[1,16]$. Smoking is a modifiable CAD risk factor that accelerates atherosclerotic plaque development and premature CAD by endothelial damage leading to reduced endothelial function [17]. Cigarette smoke directly lowers eNOS protein level and modifies enzyme activity in vivo [18]. These effects seem to differ depending on the eNOS variant because smoking-dependent eNOS genotype associations with CAD have been reported $[9,10,18]$.

Ethnic background is known to influence polymorphism frequencies and their effects on the disease. The great majority of eNOS studies were done on European or North American Caucasians and few studies have addressed the eNOS effects in Africans or their descendents [3,4]. The aim of the present study was to investigate the eNOS polymorphisms and haplotypes, and the effects of their interaction with smoking over angiographically assessed CAD in African- and Caucasian-Brazilians.

\section{Methods}

\subsection{Subjects}

A total of 715 patients (447 Caucasian-Brazilians and 268 African-Brazilians) who underwent coronary angiography due to symptoms related to CAD were studied. They were contacted at the homodynamic Unit of Santa Izabel's Hospital in Salvador, Bahia State, Brazil. Cardiologists not aware of patient genotypes interpreted the angiograms. Two hundred and sixty seven patients presented obstructive lesion-free examinations and were included as controls in our analysis. Four hundred and forty eight patients presenting $\geq 50 \%$ obstructive lesions were taken as CAD cases; among them 200 patients also presented previous MI history confirmed by ECG and/or cardiac enzymes in their medical records.
Patients with intermediate disease (obstructive lesions $<50$ ) were excluded from the study.

The population from Bahia State, in northeastern Brazil, is composed of a significant number of African descents because this state had been the major destination of African slaves in Brazil during the colonial period; the Caucasians are mostly of Portuguese descent [19]. The African ancestry was assessed by morphological facial characteristics and skin pigmentation in the interior part of the forearm as previously reported and validated to our population by classical genetic markers [20]. Using these criteria, patients were classified into Caucasian-Brazilians and African-Brazilians.

The patients underwent physical examination and provided a detailed medical history. Individuals were defined as hypertensive if their blood pressure was $>140 / 90 \mathrm{~mm} \mathrm{Hg}$ or if they were receiving any antihypertensive treatment. Individuals with a fasting glucose $\geq 126 \mathrm{mg} / \mathrm{dl}$ or those receiving any antidiabetic medication were considered diabetic. Family history was considered positive for CAD if at least one first-degree male relative was diagnosed with angina, MI, or sudden death by the age of 55 or one first-degree female relative was diagnosed with CAD by the age of 65 years. Smoking was defined as self-reported, current or past smoking. All subjects provided informed written consent approved by the Hospital Ethics Committee.

\subsection{Genotype and biochemical analysis}

Blood samples were collected for genomic DNA extraction by salting-out procedure. The T-786C and the E298D eNOS genotypes were detected by polymerase chain reactions (PCRs) followed by restriction fragment length analysis as previously described [7,11]. Homozygotes to the restriction site were used as positive controls in all reaction digestion. The 27-bp repeat polymorphism in intron 4 was detected as described by Alvarez et al. [7]. In all procedures, DNA fragments were separated by $8 \%$ polyacrylamide gel electrophoresis and visualized under ultraviolet light after ethidium bromide staining.

Total cholesterol, high-density-lipoprotein cholesterol (HDL-c), triglycerides, and glucose serum levels were measured by enzymatic methods in an autoanalyzer device using commercial kits (Weiner) in subjects under at least 12-h fasting. The low-density-lipoprotein cholesterol (LDL-c) levels were calculated by Friedewald formulae [21].

\subsection{Statistical analysis}

Allele frequencies were estimated by gene counting. The agreement of genotype frequencies with Hardy-Weinberg expectations and the pairwise linkage disequilibrium were tested by a $\chi^{2}$ goodness of fit test using Arlequin program, Version 2.000 [22]. This program was also used to estimate haplotype frequencies in CAD cases and controls from genotype frequencies using maximum likelihood methods, the estimations were done separately for Caucasian- and African- 
Brazilians. The $D^{\prime}$ values, the relative magnitude of disequilibrium $(D)$ when compared with its theoretical maximum value $\left(D / D_{\max }\right)$, were calculated as described by Lewontin [23]. The Mann-Whitney $U$-test was used to compare quantitative variables between groups. Allele and haplotype frequency differences between cases and controls were tested by Pearson $\chi^{2}$ test using the PEPI program, Version 4.0 [24]. The haplotype analyses were followed by an adjusted $\chi^{2}$ residual test to establish haplotypes that were responsible for the difference. The odds ratio estimations and the multiple logistic regressions were performed using the SPSS program Version 10 . A $p$-value $<0.05$ was considered statistically significant.

\section{Results}

Clinical and demographic characteristics of CAD cases and controls were summarized in Table 1. Cases and controls presented similar total and LDL-c levels, but triglycerides were higher and HDL-c levels were lower in cases when compared with those of controls. As expected, cases also presented higher diabetes mellitus, smoking, and early CAD family history prevalence, and were somewhat older than controls. Cases and controls were similar in the number of studied years, body mass index (BMI), and hypertension prevalence. Differences between cases and controls with respect to ethnic groups were also tested. The results showed that African-Brazilians were underrepresented among CAD cases (32.8\%) when compared with controls $(45.3 \% ; p<0.001)$.

All the eNOS genotype frequencies were according to those expected by the Hardy-Weinberg equilibrium in both ethnic groups. In African-Brazilian controls, the $-786 \mathrm{C}$, the $298 \mathrm{D}$, and the 4-repeat alleles frequencies were $21.6 \%, 22 \%$, and $19.8 \%$, respectively, whereas among Caucasian-Brazilian controls these frequencies were $32.9 \%$, $26 \%$, and $22.6 \%$, respectively. These frequency differences
Table 1

Clinical and demographic characteristics of CAD cases and controls

\begin{tabular}{llll}
\hline Variable & CAD cases $^{\mathrm{a}}$ & Controls $^{\mathrm{a}}$ & \multicolumn{1}{c}{$p$} \\
\hline Number & 448 & 267 & - \\
Age & $55.6 \pm 7.1$ & $52.5 \pm 8.2$ & $<0.001$ \\
Gender (female/male) & $148 / 300$ & $143 / 124$ & $<0.001$ \\
Diabetes mellitus & $131 / 317$ & $27 / 240$ & $<0.001$ \\
Hypertension & $335 / 113$ & $182 / 85$ & 0.068 \\
Smoking & $255 / 193$ & $121 / 146$ & 0.003 \\
Package/year & $17.6 \pm 23.6$ & $12.8 \pm 21.4$ & 0.001 \\
Early CAD family history & $169 / 279$ & $69 / 198$ & 0.001 \\
Total cholesterol (mg/dl) & $188.2 \pm 51.1$ & $186.1 \pm 43.3$ & 0.956 \\
LDL-cholesterol (mg/dl) & $125.0 \pm 44.6$ & $125.8 \pm 39.5$ & 0.546 \\
HDL-cholesterol (mg/dl) & $27.8 \pm 7.8$ & $30.7 \pm 8.6$ & $<0.001$ \\
Triglycerides (mg/dl) & $176.4 \pm 120.7$ & $148.1 \pm 85.7$ & $<0.001$ \\
Caucasian-/African-Brazilians & $147 / 301$ & $121 / 146$ & $<0.001$ \\
Studied years & $8.4 \pm 4.9$ & $7.7 \pm 4.9$ & 0.092 \\
BMI $^{\mathrm{b}}$ & $26.9 \pm 4.24$ & $26.6 \pm 4.85$ & 0.239 \\
Angina & $333 / 115$ & $209 / 58$ & 0.271 \\
\hline
\end{tabular}

${ }^{a}$ For categorical variables the values express the number of affected/nonaffected individuals.

b Current and past smoking.

${ }^{c}$ Body mass index (BMI): weight/(height) ${ }^{2}$.

between ethnic groups were significant for the $-786 \mathrm{C}$ allele only $(p=0.001)$. The $-786 \mathrm{C}$ and 298D alleles were linked in both African- $\left(D^{\prime}=0.435 ; p<0.0001\right)$ and Caucasian-Brazilians $\left(D^{\prime}=0.444 ; p<0.0001\right)$. Additionally, the 298D and the 5-repeat alleles were linked either among African- $\left(D^{\prime}=-1.000 ; p<0.0001\right)$ and Caucasian-Brazilians $\left(D^{\prime}=-0.787 ; p<0.001\right)$, whereas the $-786 \mathrm{C}$ and the 4 repeat alleles were linked in Caucasian- $\left(D^{\prime}=0.278 ; p<0.01\right)$ but not in African-Brazilians.

To avoid possible population stratification, we conducted the following analyses stratified by ethnic groups. As smoking, a known eNOS gene confounding environmental factor, also differed between CAD cases and controls, we further stratified the analyses by this factor.

Tables 2-4 list the single eNOS polymorphism frequencies in CAD cases and controls according to the smoking status in Caucasian- and African-Brazilians. Independent

Table 2

The T-786C eNOS polymorphisms frequencies in Caucasian- and African-Brazilians CAD cases and controls according to smoking status

\begin{tabular}{|c|c|c|c|c|c|c|c|c|}
\hline \multirow[t]{2}{*}{$\mathrm{T}-786 \mathrm{C}$ genotypes } & \multicolumn{4}{|l|}{ Smoking } & \multicolumn{4}{|l|}{ Nonsmoking } \\
\hline & CAD cases & Controls & $\chi^{2}$ & $p$ & CAD cases & Controls & $\chi^{2}$ & $p$ \\
\hline \multicolumn{9}{|l|}{ Caucasian-Brazilians } \\
\hline $\mathrm{TT}$ & $71(42 \%)$ & $39(63.9 \%)$ & & & $53(40.2 \%)$ & $34(40 \%)$ & & \\
\hline $\mathrm{TC}$ & $74(43.8 \%)$ & $16(26.2 \%)$ & & & $66(50 \%)$ & $34(40 \%)$ & & \\
\hline $\mathrm{CC}$ & $24(14.2 \%)$ & $6(9.8 \%)$ & & & $13(9.8 \%)$ & $17(20 \%)$ & & \\
\hline $\mathrm{C}$ allele & 0.3609 & 0.2295 & 6.462 & 0.011 & 0.3485 & 0.4000 & 0.968 & 0.325 \\
\hline Odds ratio $(95 \% \mathrm{CI})^{\mathrm{a}}$ & \multicolumn{2}{|c|}{$2.447(1.336-4.482)$} & & 0.004 & \multicolumn{2}{|c|}{$0.994(0.570-1.733)$} & & 0.982 \\
\hline \multicolumn{9}{|l|}{ African-Brazilians } \\
\hline $\mathrm{TT}$ & $40(46.5 \%)$ & $44(73.3 \%)$ & & & $29(47.5 \%)$ & $32(52.5 \%)$ & & \\
\hline $\mathrm{TC}$ & $39(45.3 \%)$ & $14(23.3 \%)$ & & & $22(36.1 \%)$ & $23(37.7 \%)$ & & \\
\hline $\mathrm{CC}$ & $7(8.1 \%)$ & $2(3.3 \%)$ & & & $10(16.4 \%)$ & $6(9.8 \%)$ & & \\
\hline $\mathrm{C}$ allele & 0.3081 & 0.1500 & 8.765 & 0.003 & 0.3443 & 0.2869 & 0.683 & 0.409 \\
\hline Odds ratio $(95 \% \mathrm{CI})^{\mathrm{a}}$ & \multicolumn{3}{|c|}{$3.162(1.552-6.445)$} & 0.002 & \multicolumn{3}{|c|}{$1.218(0.598-2.478)$} & 0.587 \\
\hline
\end{tabular}

\footnotetext{
${ }^{\text {a }}$ Odds ratio and $95 \%$ confidence interval for rarer allele carriers (homozygous + heterozygous) vs. common allele homozygous.
} 
Table 3

The 27-bp repeat eNOS frequencies in Caucasian- and African-Brazilians CAD cases and controls according to smoking status

\begin{tabular}{|c|c|c|c|c|c|c|c|c|}
\hline \multirow[t]{2}{*}{ Intron 4 repeat genotypes } & \multicolumn{4}{|l|}{ Smoking } & \multicolumn{4}{|l|}{ Nonsmoking } \\
\hline & CAD cases & Controls & $\chi^{2}$ & $p$ & CAD cases & Controls & $\chi^{2}$ & $p$ \\
\hline \multicolumn{9}{|l|}{ Caucasian-Brazilians } \\
\hline 5-Repeat 5-repeat & $113(66.9 \%)$ & $41(67.2 \%)$ & & & $89(67.4 \%)$ & $49(57.6 \%)$ & & \\
\hline 5-Repeat 4-repeat & $51(30.2 \%)$ & $19(31.1 \%)$ & & & $36(27.3 \%)$ & $27(31.8 \%)$ & & \\
\hline 4-Repeat 4-repeat & $5(3 \%)$ & $1(1.6 \%)$ & & & $7(5.3 \%)$ & $9(10.6 \%)$ & & \\
\hline 4-Repeat allele & 0.1805 & 0.1721 & 0.005 & 0.945 & 0.1894 & 0.2647 & 3.004 & 0.083 \\
\hline Odds ratio $(95 \% \mathrm{CI})^{\mathrm{a}}$ & \multicolumn{3}{|c|}{$1.016(0.545-1.895)$} & 0.960 & \multicolumn{2}{|c|}{$0.658(0.374-1.155)$} & & 0.145 \\
\hline \multicolumn{9}{|l|}{ African-Brazilians } \\
\hline 5-Repeat 5-repeat & $53(61.6 \%)$ & $32(53.3 \%)$ & & & $38(62.3 \%)$ & $43(70.5 \%)$ & & \\
\hline 5-Repeat 4-repeat & $28(32.6 \%)$ & $27(45 \%)$ & & & $22(36.1 \%)$ & $17(27.9 \%)$ & & \\
\hline 4-Repeat 4-repeat & $5(5.8 \%)$ & $1(1.7 \%)$ & & & $1(1.6 \%)$ & $1(1.6 \%)$ & & \\
\hline 4-Repeat allele & 0.2209 & 0.2417 & 0.075 & 0.785 & 0.1967 & 0.1557 & 0.452 & 0.502 \\
\hline Odds ratio $(95 \% \mathrm{CI})^{\mathrm{a}}$ & \multicolumn{3}{|c|}{$0.712(0.365-1.388)$} & 0.318 & \multicolumn{2}{|c|}{$1.446(0.679-3.078)$} & & 0.339 \\
\hline
\end{tabular}

a Odds ratio and $95 \%$ confidence interval for rarer allele carriers (homozygous + heterozygous) vs. common allele homozygous.

Table 4

The E298D eNOS frequencies in Caucasian- and African-Brazilians CAD cases and controls according to smoking status

\begin{tabular}{|c|c|c|c|c|c|c|c|c|}
\hline \multirow[t]{2}{*}{ E298D genotypes } & \multicolumn{4}{|l|}{ Smoking } & \multicolumn{4}{|l|}{ Nonsmoking } \\
\hline & CAD cases & Controls & $\chi^{2}$ & $p$ & CAD cases & Controls & $\chi^{2}$ & $p$ \\
\hline \multicolumn{9}{|l|}{ Caucasian-Brazilians } \\
\hline EE & $90(53.3 \%)$ & $34(55.7 \%)$ & & & $65(49.2 \%)$ & $49(57.6 \%)$ & & \\
\hline ED & $66(39.1 \%)$ & $22(36.1 \%)$ & & & $53(40.2 \%)$ & $28(32.9 \%)$ & & \\
\hline DD & $13(7.7 \%)$ & $5(8.2 \%)$ & & & $14(10.6 \%)$ & $8(9.4 \%)$ & & \\
\hline $\mathrm{D}$ allele & 0.2722 & 0.2623 & 0.008 & 0.927 & 0.3068 & 0.2588 & 0.939 & 0.332 \\
\hline Odds ratio $(95 \% \mathrm{CI})^{\mathrm{a}}$ & \multicolumn{3}{|c|}{$1.105(0.614-1.991)$} & 0.739 & \multicolumn{3}{|c|}{$1.403(0.810-2.429)$} & 0.227 \\
\hline \multicolumn{9}{|l|}{ African-Brazilians } \\
\hline $\mathrm{EE}$ & $44(51.2 \%)$ & $42(70 \%)$ & & & $35(57.4 \%)$ & $29(47.5 \%)$ & & \\
\hline ED & $36(41.9 \%)$ & $16(26.7 \%)$ & & & $19(31.1 \%)$ & $30(49.2 \%)$ & & \\
\hline DD & $6(7 \%)$ & $2(3.3 \%)$ & & & $7(11.5 \%)$ & $2(3.3 \%)$ & & \\
\hline D allele & 0.2791 & 0.1667 & 4.390 & 0.036 & 0.2705 & 0.2787 & 0.000 & 1.000 \\
\hline Odds ratio $(95 \% \mathrm{CI})^{\mathrm{a}}$ & \multicolumn{3}{|c|}{$2.227(1.111-4.465)$} & 0.024 & \multicolumn{3}{|c|}{$0.673(0.330-1.375)$} & 0.277 \\
\hline
\end{tabular}

a Odds ratio and $95 \%$ confidence interval for rarer allele carriers (homozygous + heterozygous) vs. common allele homozygous.

of the ethnic background, when smoking was referred, the $-786 \mathrm{C}$ allele frequency was increased in cases $(36 \%$ in Caucasian-Brazilians and $30.8 \%$ in African-Brazilians) when compared with that in controls $(23 \%, p=0.011$ in CaucasianBrazilians and 15\%, $p=0.003$ in African-Brazilians). How- ever, when smoking was negative, the $-786 \mathrm{C}$ frequency did not differ between cases and controls in both ethnic groups (Table 2). The 298D allele frequency was also increased in CAD cases $(27.9 \%)$ when compared with that in controls $(16.7 \% ; p=0.036)$ in African-Brazilians but not in

Table 5

The estimated eNOS haplotype frequencies in African- and Caucasian-Brazilians CAD cases and controls according to the smoking status

\begin{tabular}{|c|c|c|c|c|c|c|c|c|}
\hline \multirow[t]{3}{*}{ Haplotype $^{\mathrm{a}}$} & \multicolumn{4}{|c|}{ African-Brazilians } & \multicolumn{4}{|c|}{ Caucasian-Brazilians } \\
\hline & \multicolumn{2}{|l|}{ Smoking } & \multicolumn{2}{|c|}{ Nonsmoking } & \multicolumn{2}{|l|}{ Smoking } & \multicolumn{2}{|c|}{ Nonsmoking } \\
\hline & CAD cases & Controls & CAD cases & Controls & CAD cases & Controls & CAD cases & Controls \\
\hline -786T/5-repeats/298E (\%) & $46.15^{*}$ & $58.97^{*}$ & 47.93 & 48.36 & 51.34 & 53.72 & 49.43 & 42.01 \\
\hline -786T/4-repeats/298E (\%) & 13.61 & 19.66 & 11.57 & 12.30 & $5.97^{* *}$ & $12.40^{* *}$ & 7.98 & 9.47 \\
\hline -786T/5-repeats/298D (\%) & 10.65 & 5.13 & 5.79 & 11.48 & 6.27 & 10.74 & 7.60 & 8.28 \\
\hline -786C/4-repeats/298E (\%) & 7.10 & 3.42 & 7.44 & 3.28 & $11.34^{* * *}$ & $4.13^{* * *}$ & 9.89 & 16.57 \\
\hline -786C/5-repeats/298E (\%) & 6.51 & 3.42 & 6.61 & 8.20 & 4.78 & 4.13 & 4.56 & 6.51 \\
\hline$-786 \mathrm{C} / 5$-repeats/298D (\%) & 15.98 & 9.40 & 20.66 & 16.39 & 20.30 & 14.88 & 20.53 & 17.16 \\
\hline$p$ & & 0.043 & & 0.407 & & 0.018 & & 0.256 \\
\hline
\end{tabular}

a The rare (less than 1.5\%) -786C/4-repeats/298D and -786T/4-repeats/298D haplotypes were excluded from analysis due low number.

* Significant adjusted $\chi^{2}$ residues $(p=0.033)$.

** Significant adjusted $\chi^{2}$ residues $(p=0.023)$.

*** Significant adjusted $\chi^{2}$ residues $(p=0.020)$. 
Table 6

The multiple logistic regression for CAD risk in Brazilians

\begin{tabular}{|c|c|c|c|c|c|c|}
\hline Variable & $\beta$ & S.E. & Wald & Odds ratio & $95 \% \mathrm{CI}$ & $p$ \\
\hline Age (years) & 0.048 & 0.012 & 16.094 & 1.049 & $1.025-1.074$ & $<0.001$ \\
\hline Male gender & 1.022 & 0.197 & 27.043 & 2.780 & $1.891-4.087$ & $<0.001$ \\
\hline Early CAD history & 0.529 & 0.196 & 7.300 & 1.697 & $1.156-2.491$ & 0.007 \\
\hline African-Brazilians & -0.523 & 0.185 & 8.019 & 0.592 & $0.412-0.851$ & 0.005 \\
\hline Diabetes mellitus & 1.416 & 0.255 & 30.845 & 4.122 & $2.500-6.794$ & $<0.001$ \\
\hline LDL-c level (mg/dl) & 0.005 & 0.002 & 5.199 & 1.005 & $1.001-1.010$ & 0.023 \\
\hline HDL-c level (mg/dl) & -0.030 & 0.012 & 6.227 & 0.970 & $0.948-0.994$ & 0.013 \\
\hline Triglycerides level (mg/dl) & 0.002 & 0.001 & 6.462 & 1.002 & $1.001-1.004$ & 0.011 \\
\hline Hypertension & 0.497 & 0.209 & 5.638 & 1.643 & $1.091-2.476$ & 0.018 \\
\hline Smoking & -0.175 & 0.251 & 0.485 & 0.839 & $0.513-1.374$ & 0.486 \\
\hline$-786 \mathrm{C}$ eNOS carriers ${ }^{\mathrm{a}}$ & -0.109 & 0.249 & 0.192 & 0.897 & $0.551-1.460$ & 0.661 \\
\hline Interaction with smoking ${ }^{\mathrm{b}}$ & 1.077 & 0.360 & 8.949 & 2.935 & $1.450-5.944$ & 0.003 \\
\hline
\end{tabular}

Variables that do not remain as significant coronary artery disease (CAD) predictors: 298D carriers, interaction between 298D allele carriers (DD + ED) vs. smoking; 4-repeat allele carriers (4-repeat 4-repeat + 5-repeat 4-repeat), interaction between 4-repeat allele carriers vs. smoking; the number of studied years; body mass index (BMI).

a $\mathrm{CC}+\mathrm{TC}$.

b $-786 \mathrm{C}$ carriers $\times$ smoking.

Caucasian-Brazilians, again in a smoking-dependent way (Table 3). The 27-pb repeat (intron 4) eNOS polymorphism was not associated with CAD (Table 4).

Table 5 lists the maximum likelihood estimation of eNOS haplotype frequencies in cases and controls according to the ethnic group and smoking status. Either in Africanor Caucasian-Brazilians, the haplotype frequencies differed between cases and controls in a smoking-dependent way. In African-Brazilian smokers, the adjusted $\chi^{2}$ residues indicated that the $-786 \mathrm{~T} / 5$-repeat/298E haplotype frequency was decreased in cases $(46.15 \%)$ when compared with that in controls $(58.97 \%$; $p=0.033)$. In Caucasian-Brazilian smokers, the $-786 \mathrm{C} / 4$-repeat/298E haplotype frequency was higher and -786T/4-repeat/298E was lower in cases $(11.34 \%$ and $5.97 \%$, respectively) when compared with that in controls ( $4.13 \%, p=0.020$ and $12.40 \%, p=0.023$, respectively).

A multiple logistic regression analysis that included all samples showed evidence that interaction between the $-786 \mathrm{C}$ carrier genotypes $(-786 \mathrm{CC}+-786 \mathrm{TC})$ and smoking increased the risk of $\mathrm{CAD}$ (odds ratio: 2.9 , 95\% CI: $1.4-5.9 ; p=0.003$ ) in Brazilians. The interaction was independent and corrected to other risk factors that remained significant in the model, including ethnic groups. The other eNOS polymorphisms and their interaction with smoking were not significantly independent of CAD predictors and could not remain in the model (Table 6).

\section{Discussion}

This study focused on the important topic of genetic susceptibility to CAD and the environmental factors that modify such associations. The main finding of the present report was to demonstrate the smoking-dependent effect of eNOS gene on angiographically assessed CAD in African-Brazilians for the first time. This study also corroborated a previous report on the eNOS gene association with CAD in Caucasians from the southern-Brazilian region [8], strongly suggesting that the eNOS gene variability influences CAD susceptibility in Brazilians in a smoking-dependent manner regardless of the ethnic background.

Overall, the eNOS allele frequencies showed in controls are in the same range as those previously reported in the same ethnic group among Brazilians [8,15,25] and other populations $[7,26]$. However, some eNOS polymorphism frequencies were somewhat different from those reported by Marroni et al. [25]. Differences in ethnic background and demographic histories between the Brazilian regions from where these studies were carried out can contribute to the prevailing inconsistencies. In the present report, Africanand Caucasian-Brazilians showed similar 298D and 4-repeat eNOS allele frequencies, but the $-786 \mathrm{C}$ allele was more common in Caucasian-Brazilians as reported previously [15]. The pattern of linkage disequilibrium in the eNOS gene was also similar in both Brazilian ethnic groups, except for the promoter and 27-bp repeat variants that were linked in Caucasians and randomly associated in African-Brazilians as shown by others [15].

The $-786 \mathrm{C}$ allele was associated with CAD in both Caucasian- and African-Brazilians in a smoking-dependent manner. Alvarez et al. [7] reported similar findings in Caucasian smokers from Spain, and the association in CaucasianBrazilians also corroborated a previous report in Brazilians of European descent and other populations [6,8]. In Africans and their descendents, there were few studies on eNOS variants and their effect on CAD [26] and there was no analysis yet on the $-786 \mathrm{C}$ allele interaction with smoking. The 298D allele was not associated with CAD in Caucasian-Brazilians as previously reported [8], but in African-Brazilians, the risk of CAD increased in a smoking-dependent manner. The E298D eNOS variant is a conservative mutation in a region not directly involved with enzyme catalytic function or substrate interaction. As the 298D was linked with the $-786 \mathrm{C}$ promoter mutation in African-Brazilians, and as it 
did not remain as an independent $\mathrm{CAD}$ predictor after including the $-786 \mathrm{C}$ in the multiple logistic regression model, it is possible that its effect on CAD could be due to the linkage with the promoter mutation, as previously reported [8].

Wang et al. [9] were the first to report the 4-repeat allele effect on CAD in a smoking-dependent manner in Australian Caucasians, but single-locus analysis in Caucasianand African-Brazilians could not reveal such an association. However, haplotype analysis showed that the 4-repeat allele in association with the $-786 \mathrm{C}$ promoter mutation forming the $-786 \mathrm{C} / 4$-repeat/298E haplotype increased the CAD risk in Caucasian-Brazilian smokers. Conversely, the 4-repeat allele in association with the $-786 \mathrm{~T}$ variant in $-786 \mathrm{~T} / 4$ repeat/298E haplotype had a protective effect in the same group. This indicates that the effect of 4-repeat variant is modified from risk to protection depending on the haplotype formed with the promoter polymorphism $(\mathrm{T}-786 \mathrm{C})$. The lack of association of these specific haplotypes and CAD in African-Brazilians may be explained by the fact that the $-786 \mathrm{C}$ and 4-repeat alleles were not linked in this ethnic group; however, the wild -786T/5-repeat/298E haplotype showed a protective effect on the disease in this group.

Functional assays with the $-786 \mathrm{C}$ eNOS promoter showed a $50 \%$ reduction in transcription efficiency when compared with the $-786 \mathrm{~T}$ promoter. Adding cigarette smoke to the culture media further increased this difference $[6,27]$. Cigarette smoke is a rich source of exogenous nitric oxide that can affect endogenous nitric oxide by downregulating its production [28]. These findings suggest a functional mechanism to the observed interaction between the promoter T-786C polymorphism and smoking in the effect on $\mathrm{CAD}$ risk detected herein. Additionally, tests using luciferase reporter assay constructs with different $\mathrm{T}-786 \mathrm{C}$ promoters and 27-bp repeat variants in intron 4 showed different haplotype effects on transcriptional efficiency modifiable by cigarette smoke, suggesting that the intron 4 repeat has different $c i s$-regulating effects on promoter efficiency depending on the T-786C polymorphism and smoking [27].

The results of our study should be interpreted in the context of some limitations. The control group used in the current study comprises lesion-free people referred for the coronary angiogram due to certain coronary disease symptoms such as angina. In the present study, the eNOS polymorphisms were not associated with angina in both lesion-free controls and CAD cases even after stratifying to the smoking status (data not shown) not suggesting this as a potential bias. Although there was a higher male/female ratio in CAD cases than in controls, such differences apparently did not affect the eNOS association detected herein as gender was included in the multivariate logistic regression analysis without modifying the eNOS effect and its interaction with smoking. The stratification of analysis by smoking and ethnic groups did not seem to compromise the statistical power to detect or exclude eNOS association within each stratum. The calculated statistical power under the significance level of 0.05 and using the number of individuals and ORs detected herein varied from $82.2 \%$ to $91.7 \%$ among subgroups.

The present study on angiographically assessed CAD in Caucasian- and African-Brazilians suggested that smoking interacted with the $-786 \mathrm{C}$ eNOS promoter variant increasing the CAD risk in both ethnic groups. For the first time, this effect was demonstrated in an African-derived group. Additionally, in Caucasian-Brazilian smokers, the -786T/4repeat/298E and the $-786 \mathrm{C} / 4$-repeat/298E haplotypes presented protective and susceptible CAD effects, respectively, whereas the $-786 \mathrm{~T} / 5$-repeat/298E haplotype had a protective effect among African-Brazilian smokers.

\section{Acknowledgments}

We thank the cardiologists from Santa Izabel Hospital's Hemodynamic Unit for providing the assessment of their patients, and to the nurses for their assistance in the collection of blood samples. This study was supported by the Fundação de Amparo a Pesquisa do Estado da Bahia (FAPESB) and by the Conselho Nacional de Desenvolvimento Científico e Tecnológico (CNPq).

\section{References}

[1] Peyser PA. Genetic epidemiology of coronary artery disease. Epidemiol Rev 1997;19(1):80-90.

[2] Napoli C, Ignarro LJ. Nitric oxide and atherosclerosis. Nitric Oxide 2001;5(2):88-97.

[3] Hingorani AD. Polymorphisms in endothelial nitric oxide synthase and atherogenesis: John French Lecture 2000. Atherosclerosis 2001;154(3):521-7.

[4] Wang XL, Wang J. Endothelial nitric oxide synthase gene sequence variations and vascular disease. Mol Genet Metab 2000;70(4):241-51.

[5] Casas JP, Bautista LE, Humphries SE, Hingorani AD. Endothelial nitric oxide synthase genotype and ischemic heart disease: metaanalysis of 26 studies involving 23,028 subjects. Circulation 2004;109:1359-65.

[6] Miyamoto Y, Saito Y, Nakayama M, et al. RPA1 represses the eNOS gene with T-786C mutations: a molecular mechanism for predisposition to coronary spastic angina. Circulation 1999;100(suppl. I): I-754.

[7] Alvarez R, Gonzalez P, Batalla A, et al. Association between the NOS3 $(-786 \mathrm{~T} / \mathrm{C})$ and the ACE (I/D) DNA genotypes and early coronary artery disease. Nitric Oxide 2001;5(4):343-8.

[8] Rios DL, Callegari-Jacques SM, Hutz MH. Endothelial nitric oxide synthase and fractalkine chemokine receptor polymorphisms on angiographically assessed coronary atherosclerosis. Clin Chim Acta 2005;362(1-2):138-46.

[9] Wang XL, Sim AS, Badenhop RF, McCredie RM, Wilcken DE. A smoking-dependent risk of coronary artery disease associated with a polymorphism of the endothelial nitric oxide synthase gene. Nat Med 1996;2(1):41-5.

[10] Leeson CP, Hingorani AD, Mullen MJ, et al. Glu298Asp endothelial nitric oxide synthase gene polymorphism interacts with environmental and dietary factors to influence endothelial function. Circ Res 2002;90(11):1153-8.

[11] Hingorani $\mathrm{AD}$, Liang $\mathrm{CF}$, Fatibene $\mathrm{J}$, et al. A common variant of the endothelial nitric oxide synthase (Glu298 $\rightarrow$ Asp) is a major risk factor for coronary artery disease in the UK. Circulation 1999;100(14):1515-20. 
[12] Colombo MG, Andreassi MG, Paradossi U, et al. Evidence for association of a common variant of the endothelial nitric oxide synthase gene (Glu298 $\rightarrow$ Asp polymorphism) to the presence, extent, and severity of coronary artery disease. Heart 2002;87(6):525-8.

[13] Gardemann A, Lohre J, Cayci S, et al. The T allele of the missense Glu(298)Asp endothelial nitric oxide synthase gene polymorphism is associated with coronary heart disease in younger individuals with high atherosclerotic risk profile. Atherosclerosis 2002;160(1):16775 .

[14] Granath B, Taylor RR, van Bockxmeer FM, Mamotte CD. Lack of evidence for association between endothelial nitric oxide synthase gene polymorphisms and coronary artery disease in the Australian Caucasian population. J Cardiovasc Risk 2001;8(4):235-41.

[15] Sandrim VC, Coelho EB, Nobre F, et al. Susceptible and protective eNOS haplotypes in hypertensive black and white subjects. Atherosclerosis [available online in 2005 September 14].

[16] Talmud PJ, Humphries SE. Genetic polymorphisms, lipoproteins and coronary artery disease risk. Curr Opin Lipidol 2001;12(4):405-9.

[17] Poredos P, Orehek M, Tratnik E. Smoking is associated with doserelated increase of intima-media thickness and endothelial dysfunction. Angiology 1999;50(3):201-8.

[18] Wang XL, Sim AS, Wang MX, et al. Genotype dependent and cigarette specific effects on endothelial nitric oxide synthase gene expression and enzyme activity. FEBS Lett 2000;471(1):45-50.

[19] Tavares LHD. Historia da Bahia. 10th ed. São Paulo/Salvador, Brazil UNESP/EDUFBA Publishers; 2001, 542 pp.
[20] Azevedo ES. Subgroup studies of black admixture within a mixed population of Bahia, Brazil. Ann Hum Genet 1980;44(Pt 1):55-60.

[21] Friedewald WT, Levy RI, Fredrickson DS. Estimation of the concentration of low-density lipoprotein cholesterol in plasma, without use of the preparative ultracentrifuge. Clin Chem 1972;18(6):499-502.

[22] Schneider S, Roessli D, Excoffier L. Arlequin Ver. 2000: a software for populations genetics analysis. Switzerland: Genetics and Biometry Laboratory, University of Geneva; 2000.

[23] Lewontin RC. On measures of gametic disequilibrium. Genetics 1988;1,20(3):849-52.

[24] Abramson JH, Gahlinger PM. Computer programs for epidemiologists: PEPI, Version 4.0. Salt Lake City: Sagebrush Press; 2001.

[25] Marroni AS, Metzger IF, Souza-Costa DC, et al. Consistent interethnic differences in the distribution of clinically relevant endothelial nitric oxide synthase genetic polymorphisms. Nitric Oxide 2005;12:177-82.

[26] Hooper WC, Lally C, Austin H, et al. The relationship between polymorphisms in the endothelial cell nitric oxide synthase gene and the platelet GPIIIa gene with myocardial infarction and venous thromboembolism in African Americans. Chest 1999;116(4): 880-6.

[27] Wang J, Dudley D, Wang XL. Haplotype-specific effects on endothelial NO synthase promoter efficiency: modifiable by cigarette smoking. Arterioscler Thromb Vasc Biol 2002;22(5):e1-4.

[28] Sarkar R, Gelabert HA, Mohiuddin KR, Thakor DK, SantibanezGallerani AS. Effect of cigarette smoke on endothelial regeneration in vivo and nitric oxide levels. J Surg Res 1999;82(1):43-7. 